\title{
Erratum to: Testing Kerr black hole mimickers with quasi-periodic oscillations from GRO J1655-40
}

\author{
Xin Jiang ${ }^{1, \mathrm{a}} \mathbb{C}_{0}$, Peng Wang ${ }^{1, \mathrm{~b}}$, Houwen Wu ${ }^{1,2, \mathrm{c}}$, Haitang Yang ${ }^{1, \mathrm{~d}}$ \\ ${ }^{1}$ Center for Theoretical Physics, College of Physics, Sichuan University, Chengdu 610064, China \\ 2 Department of Applied Mathematics and Theoretical Physics, University of Cambridge, Wilberforce Road, Cambridge CB3 0WA, UK
}

Published online: 4 January 2022

(C) The Author(s) 2021

Erratum to: Eur. Phys. J. C (2021) 81:1043

https://doi.org/10.1140/epjc/s10052-021-09816-z

In this article, the order that the authors appeared in the author list was incorrect. The correct order is as follows:

Xin Jiang, Peng Wang, Houwen Wu and Haitang Yang.

The original article has been corrected.

\begin{abstract}
Open Access This article is licensed under a Creative Commons Attribution 4.0 International License, which permits use, sharing, adaptation, distribution and reproduction in any medium or format, as long as you give appropriate credit to the original author(s) and the source, provide a link to the Creative Commons licence, and indicate if changes were made. The images or other third party material in this article are included in the article's Creative Commons licence, unless indicated otherwise in a credit line to the material. If material is not included in the article's Creative Commons licence and your intended use is not permitted by statutory regulation or exceeds the permitted use, you will need to obtain permission directly from the copyright holder. To view a copy of this licence, visit http://creativecomm ons.org/licenses/by/4.0/.

Funded by SCOAP ${ }^{3}$.
\end{abstract}

The original article can be found online at https://doi.org/10.1140/ epjc/s10052-021-09816-z.

\footnotetext{
a e-mail: xjang@stu.scu.edu.cn (corresponding author)

be-mail: pengw@scu.edu.cn

c e-mail: hw598@damtp.cam.ac.uk

de-mail: hyanga@scu.edu.cn
} 